\title{
NPP vulnerability of the potential vegetation of China to climate change in the past and future
}

\author{
YUAN Quanzhi ${ }^{1,2}$, "WU Shaohong ${ }^{3,4}$, DAI Erfu ${ }^{3,4}$, ZHAO Dongsheng ${ }^{3,4}$, \\ REN Ping ${ }^{1,2}$, ZHANG Xueru ${ }^{5}$ \\ 1. Key Lab of Land Resources Evaluation and Monitoring in Southwest, Ministry of Education, Sichuan Normal \\ University, Chengdu 610068, China; \\ 2. Institute of Geography and Resources Science, Sichuan Normal University, Chengdu 610101, China; \\ 3. Institute of Geographic Sciences and Natural Resources Research, CAS, Beijing 100101, China; \\ 4. Key Laboratory of Land Surface Pattern and Simulation, CAS, Beijing 100101, China; \\ 5. Chongqing Jiaotong University, Chongqing 400074, China
}

\begin{abstract}
Using the Integrated Biosphere Simulator, a dynamic vegetation model, this study initially simulated the net primary productivity (NPP) dynamics of China's potential vegetation in the past 55 years (1961-2015) and in the future 35 years (2016-2050). Then, taking the NPP of the potential vegetation in average climate conditions during 1986-2005 as the basis for evaluation, this study examined whether the potential vegetation adapts to climate change or not. Meanwhile, the degree of inadaptability was evaluated. Finally, the NPP vulnerability of the potential vegetation was evaluated by synthesizing the frequency and degrees of inadaptability to climate change. In the past 55 years, the NPP of desert ecosystems in the south of the Tianshan Mountains and grassland ecosystems in the north of China and in western Tibetan Plateau was prone to the effect of climate change. The NPP of most forest ecosystems was not prone to the influence of climate change. The low NPP vulnerability to climate change of the evergreen broad-leaved and coniferous forests was observed. Furthermore, the NPP of the desert ecosystems in the north of the Tianshan Mountains and grassland ecosystems in the central and eastern Tibetan Plateau also had low vulnerability to climate change. In the next 35 years, the NPP vulnerability to climate change would reduce the forest-steppe in the Songliao Plain, the deciduous broad-leaved forests in the warm temperate zone, and the alpine steppe in the central and western Tibetan Plateau. The NPP vulnerability would significantly increase of the temperate desert in the Junggar Basin and the alpine desert in the Kunlun Mountains. The NPP vulnerability of the subtropical evergreen broad-leaved forests would also increase. The area of the regions with increased vulnerability would account for $27.5 \%$ of China.
\end{abstract}

Keywords: climate change; vulnerability; potential vegetation; net primary productivity; IBIS; China

Received: 2016-08-22 Accepted: 2016-09-20

Foundation: Key Project of National Natural Science Foundation of China, No.41530749; Science and Technology Project of Sichuan Provincial Department of Education, No.15ZB0023; Youth Projects of National Natural Science Foundation of China, No.41301196, No.41501202; Chongqing Foundation and Advanced Research Project, No.cstc2014jcyjA0808

Author: Yuan Quanzhi, PhD, specialized in physical geography. E-mail: yuanqz@sicnu.edu.cn.

"Corresponding author: Wu Shaohong, Professor, specialized in physical geography. E-mail: wush@igsnrr.ac.cn 


\section{Introduction}

Vulnerability is the tendency or habit of things to suffer from adverse effects, including the sensitivity or susceptibility to hazards and the lack of ability to cope and adapt (IPCC, 2014). Vulnerability assessment can be a basis for decision-making to continue the sustainable development of the system, reduce the adverse effects of external stress on the system, and comprehensively improve the degradation system (Cai et al., 1996; Fang et al., 2016). The strong climate change has greatly affected the distribution, productivity, and service function of China's natural ecosystems (Wu et al., 2014). Revealing and predicting the vulnerability of China's natural ecosystems under climate change have become important topics for domestic scholars (Liu and Li, 2007; Tian and Chang, 2012).

Potential vegetation, which can reflect the general trend of vegetation development, is the most stable and mature vegetation type without human interference in the current climate conditions (Tüexen, 1956). The increasing significance of the direct effect of human activities on natural ecosystems adds to the difficulty of separating its relationship with the effect of climate change on natural ecosystems. Accordingly, based on the potential vegetation using model simulation to evaluate the vulnerability of natural ecosystems in China has become a common view of many scholars (Wu et al., 2007; Yu et al., 2008; Zhao and Wu, 2014).

Net primary productivity (NPP) is the amount of organic matter accumulated by green plants in an area per unit time (Lieth et al., 1975). NPP not only reflects the production capacity of ecosystems directly, but also serves as the main criterion for carbon source/sink. This study uses a climate-vegetation model to evaluate the NPP vulnerability of the potential vegetation in the past and future climate changes by simulating the NPP changes of the potential vegetation in the past 55 (1961-2015) and the next 35 years (2016-2050). The results can provide a scientific basis for the rational evaluation and prediction of the adverse effects of climate change on natural ecosystems necessary in taking targeted measures to mitigate and adapt to climate change for the conservation and restoration of natural ecosystems.

\section{Model and data}

\subsection{Model}

Climate-vegetation model is the main tool employed to investigate the interaction between vegetation and climate on regional and global scales. The model can be used to analyze the vegetation characteristic parameters, structure, and function of natural ecosystems, as well as the influence of the interaction between vegetation and climate change ( $\mathrm{Li}$ et al., 2009). The models can be divided into biogeographical, biogeochemical, and coupled atmosphere-biosphere models. Biogeographical models determine the competition and distribution of plant functional types by setting the growing degree days, extreme minimum temperature, and other ecological physiological conditions, such as BIOME1 (Prentice et al., 1992) and MAPPS (Neilson et al., 1995). However, these models cannot simulate the dynamic processes of vegetation change over time and cannot reflect the hysteresis of vegetation response to environmental changes. Biogeochemical models, such as CENTURY (Par- 
ton et al., 1993) and DOLY (Woodward et al., 1995), can be used to calculate the carbon and nutrient cycle in plant-soil-atmosphere by simulating photosynthesis, respiration, and soil microbial decomposition processes. Although biogeochemical models compensate for the failure of the equilibrium model to describe the dynamic processes between vegetation and environment, these models cannot simulate the changes in vegetation composition and structure caused by long-term climate change. Coupled atmosphere-biosphere models consider the dynamic processes of vegetation and environment as well as the hysteretic response of vegetation to environmental change, which can simulate the instantaneous change of vegetation and the dynamic effects of climate, such as the Integrated Biosphere Simulator (IBIS) (Foley et al., 1996) and Lund-Potsdam-Jena Dynamic Global Vegetation Model (LPJ-DGVM) (Sitch et al., 2003). Coupled models have become an important development direction in the study of climate-vegetation relationship.

As a DGVM, IBIS is capable of simulating the dynamic process between atmosphere and vegetation by integrating a series of biophysical and biogeochemical processes in the terrestrial biosphere, such as surface physical processes, canopy physiological characteristics, plant phenology, vegetation dynamics, carbon cycle, and nitrogen cycle (Kucharik et al., 2000). Yuan et al. $(2011,2014)$ adjusted the parameters of IBIS, enabling the model to create a more accurate simulation of the potential vegetation pattern and NPP. Based on the modified IBIS model, this study evaluates the NPP vulnerability of China's potential vegetation under climate change.

\subsection{Data}

In this paper, the input and output data resolutions of the model were both $0.5^{\circ} \times 0.5^{\circ}$. The input data included terrain data, soil data, and meteorological data.

(1) Terrain data: These data were a resampling from China's DEM, the resolution of which was 30".

(2) Soil data: Soil texture data were obtained from IGBP-DIS (1999), including six soil layers $(0.15,0.25,0.10,0.50,1$, and $2.00 \mathrm{~m}$ from top to bottom).

(3) Climate data: The meteorological data required for the model, including monthly mean temperature, monthly mean maximum temperature, monthly mean minimum temperature, monthly extreme minimum temperature, monthly precipitation, monthly rainy days, monthly mean relative humidity, monthly mean wind speed, and monthly mean sunshine percentage. The historical meteorological data were from 756 meteorological stations in China. The spatial interpolation of the meteorological data was based on ANUSPLIN software, which has been widely used in related research (Hutchinson, 1991). Interpolation results showed that the percentage of sunshine, temperature, relative humidity, precipitation, and rainy days were in high fitting degrees (observed and simulated values of $R^{2}>0.9, p<$ 0.05 ). The fitting degree of wind speed was slightly poor (observed and simulated values of $R^{2}>0.8, p<0.05$ ), but satisfied the requirement of this research.

The IPCC fifth assessment report (AR5) used the Representative Concentration Pathways (RCPs) scenario data combined with policy factors. The meteorological data for 2016-2050 were simulated data under the RCP4.5 scenario. The RCPs scenario is represented by an approximate total radiative stress of 2100 with respect to 1750 . RCP2.6 is a very low radiative stress level of mitigation scenarios. RCP6.0 and RCP4.5 are both medium stabilization 
scenarios, but the priority of RCP4.5 is greater than RCP6.0. RCP8.5 is a very high greenhouse gas emission scenario (Moss et al., 2010). The time variation of greenhouse gas emission under the RCP4.5 scenario is more consistent with China's future economic development trend. In this paper, the RCP4.5 scenario data were the integration of five models with unequal weights in CMIP5, including GFDL-ESM2M, HadGEM2-ES, IPSL-CM5A-LR, MIROC-ESM-CHEM, and NorESM1-M.

\subsection{Sensitivity analysis of climatic factors}

The sensitivity analysis of climatic factors is a means to study the response degree of the model that can result from the change of input climatic factors, which were important bases for the analysis and discussion of the simulation results. Relative sensitivity algorithm was employed in this study to analyze the sensitivity of the simulated NPP with respect to the climatic element inputs as follows:

$$
S=\frac{\sum_{i=1}^{n} \frac{\left(Q_{i+1}-Q_{i}\right) / Q_{b}}{\left(P_{i+1}-P_{i}\right) / 100}}{n+1},
$$

where $S$ is the relative sensitivity, $P_{i}$ and $P_{i+1}$ are the adjustment rates of input data at the $i$ and $i+1$ times, $Q_{b}$ is the output of the model in the original input data, $Q_{i}$ and $Q_{i+1}$ are the outputs of the model at the $i$ and $i+1$ time calculations.

Calculation results showed that the NPP of tropical and boreal trees was sensitive to temperature changes because of the small distribution areas of tropical and boreal trees in China. The changes in the distribution areas of the two types of plant functional types (PFTs) caused by temperature variation would lead to a large relative change in the amount of NPP. The NPP sensitivities of most PFTs to temperature difference, wind speed, and rainy day changes were low, while the sensitivities to precipitation, relative humidity, and cloudiness changes were moderate (Table 1).

Table 1 Sensitivity analysis of climatic data input

\begin{tabular}{lcccccccc}
\hline \multirow{1}{*}{ PFTs } & \multicolumn{7}{c}{ NPP sensitivity to climatic factors change } \\
\cline { 2 - 7 } & $\begin{array}{c}\text { Tempera- } \\
\text { ture } \\
\left({ }^{\circ} \mathrm{C}\right)\end{array}$ & $\begin{array}{c}\text { Tempera- } \\
\text { ture dif- } \\
\text { ference } \\
\left({ }^{\circ} \mathrm{C}\right)\end{array}$ & $\begin{array}{c}\text { Precipita- } \\
\text { tion } \\
(\mathrm{mm})\end{array}$ & $\begin{array}{c}\text { Relative } \\
\text { humidity } \\
(\%)\end{array}$ & $\begin{array}{c}\text { Cloudi- } \\
\text { ness } \\
(\%)\end{array}$ & $\begin{array}{c}\text { Wind } \\
\text { speed } \\
(\mathrm{m} / \mathrm{s})\end{array}$ & $\begin{array}{c}\text { Rainy } \\
\text { day } \\
(\mathrm{d})\end{array}$ \\
\hline Tropical evergreen broad-leaved forest & 5.229 & -0.032 & 0.375 & 0.682 & -0.278 & 0.011 & -0.219 \\
Tropical rain and evergreen broad-leaved forest & 6.818 & -0.037 & 0.361 & 0.692 & -0.277 & 0.013 & -0.216 \\
Subtropical evergreen broad-leaved forest & -0.684 & -0.040 & 0.174 & 0.442 & -0.141 & -0.002 & -0.045 \\
Temperate coniferous evergreen forest & -0.026 & -0.081 & 0.553 & 1.082 & 0.184 & -0.053 & -0.092 \\
Temperate deciduous broad-leaved forest & 0.001 & -0.086 & 0.656 & 0.733 & 0.186 & -0.033 & -0.064 \\
Boreal coniferous evergreen forest & -1.876 & -0.062 & 0.292 & 0.886 & -0.082 & -0.040 & -0.051 \\
Boreal broad-leaved cold-deciduous forest & -4.010 & -0.093 & 0.654 & 0.759 & 0.136 & -0.039 & -0.069 \\
Boreal coniferous cold-deciduous forest & -4.311 & -0.073 & 0.356 & 0.572 & 0.012 & -0.030 & -0.040 \\
Evergreen shrubs & -0.480 & -0.097 & 0.371 & 0.324 & -0.764 & -0.163 & 0.120 \\
Cold-deciduous shrubs & -0.485 & -0.069 & 0.212 & 0.261 & -0.686 & -0.031 & 0.176 \\
Warm (C4) grasses & 3.601 & -0.020 & 0.559 & 0.611 & -1.916 & -0.049 & 0.390 \\
Cool (C3) grasses & -1.590 & -0.116 & 0.348 & 0.510 & -0.022 & -0.042 & -0.035 \\
\hline
\end{tabular}




\section{Vulnerability}

\subsection{Method}

Vulnerability assessment of a system generally requires a comparison of the system's normal, which is the assessment benchmark (Metzger et al., 2008). Referring to the standard climatic period defined in the IPCC fifth assessment report, this paper sets the average climate conditions during 1986-2005 as the standard annual climate. Using the potential vegetation's NPP in this climate condition as the assessment benchmark, the vulnerability of the potential vegetation to historical and future climate changes was quantitatively assessed.

The NPPs of natural ecosystems have normal fluctuation ranges. Through the years of NPP simulation of European natural ecosystems under climate change, Minnen et al. (2002) found that about $80 \%$ of the NPP fluctuations were within the $\pm 10 \%$ of the average NPP. Therefore, the NPP fluctuation over $10 \%$ of the average was taken as the threshold to ascertain the fragility of the system. Shi (2009) simulated the normal NPP fluctuation range of China's natural ecosystems using the GloPEM and AVIM2 models. The calculated results were $+9.9 \%$ and $+8.5 \%$, respectively, which were similar to the research results of Minnen et al. (2002). Thus, the vegetation in this study was considered inadaptable to climate change if the NPP fluctuation was lower than the assessment benchmark of $10 \%$. In accordance with the degree of NPP fluctuation, the level of inadaptability was divided into mild $(-40 \% \leqslant \Delta \mathrm{NPP}<-10 \%)$, moderate $(-60 \% \leqslant \Delta \mathrm{NPP}<-40 \%)$, severe $(-80 \% \leqslant \Delta \mathrm{NPP}<-60 \%)$, and extreme $(\Delta \mathrm{NPP}<-80 \%)(\mathrm{Wu}$ et al., 2005$)$. This paper assessed the vulnerability by synthesizing the frequency and degree of inadaptability to climate change of the potential vegetation. The calculation formula is as follows:

$$
V=\frac{\sum_{i=1}^{n} A_{j}}{n},
$$

where $V$ represents the vulnerability score, $i$ is the $i($ th) year, $j$ is the inadaptability level to climate change of the potential vegetation, $A_{j}$ represents the grade of the inadaptability to climate change of the potential vegetation in year $i$ ( 1 for mild, 2 for moderate, 3 for sever, and 4 for extreme). According to the vulnerability assessment score, this study divided the vulnerability levels as follows: lowest vulnerability (0-0.4), lower vulnerability (0.4-0.8), higher vulnerability $(0.8-1.6)$, and highest vulnerability $(>1.6)$.

\subsection{Results and analysis}

3.2.1 NPP vulnerability of potential vegetation under historical climate change

Under the climate change during 1961-2015, the highest vulnerability areas of the potential vegetation in China were mainly located in the temperate desert regions south of the Tianshan Mountains, which accounted for $8.7 \%$ of the total area of China. The higher vulnerability areas were mainly located in temperate steppe regions, alpine grassland regions in Qiangtang Plateau, and deciduous broad-leaved forest regions in central southern Hebei, which accounted for $17.8 \%$ of the total area of China. The lower vulnerability areas were 
mainly concentrated in the warm temperate deciduous broad-leaved forest regions, alpine grassland regions in central Tibetan Plateau, subtropical evergreen broad-leaved forest regions in the south of Nanling Mountains, and tropical and monsoon rain forest areas, which accounted for $29.0 \%$ of the total area of China. The lowest vulnerability areas mainly included the cold temperate coniferous forest regions, temperate desert regions of northern Tianshan Mountains, temperate coniferous and deciduous broad-leaved mixed forest regions, alpine desert regions in the northern Tibetan Plateau, alpine meadow regions in the eastern Tibetan Plateau, coniferous forest regions in Hengduan Mountains, subtropical evergreen broad-leaved regions in the north of Nanling Mountains, and evergreen broad-leaved forests in the Yunnan-Guizhou (Yungui) Plateau and Sichuan Basin, which accounted for $44.5 \%$ of the total area of China (Figure 1).

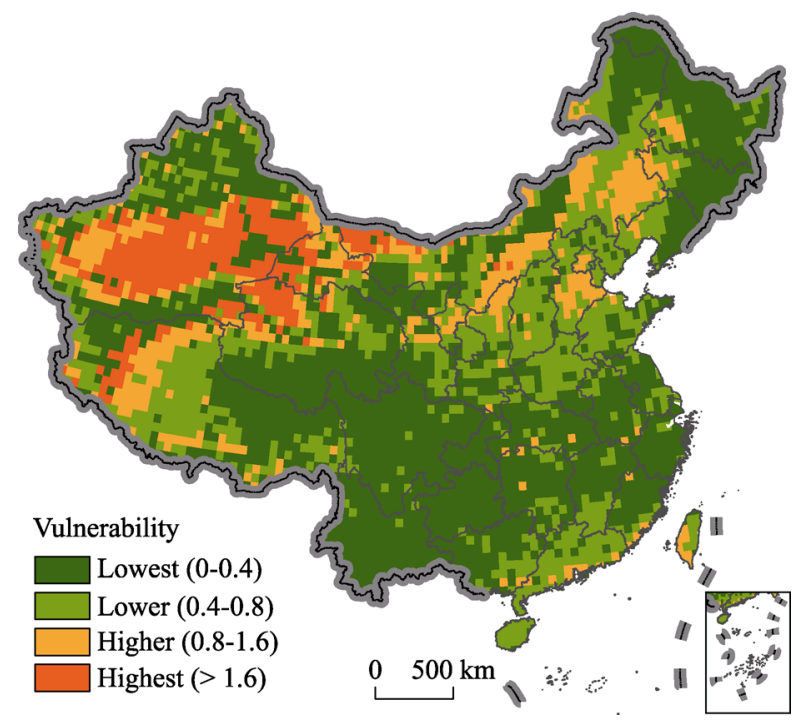

Figure 1 Natural ecosystems' vulnerability to climate change over the past 55 years in China

The vegetation was sparse and the structure of ecosystems was too simple in the Alashan regions of Inner Mongolia, Hexi Corridor of Gansu Province, Tarim Basin in Xinjiang, and Qaidam Basin in Qinghai Province. Therefore, the NPP vulnerability to climate change of the potential vegetation in these desert regions was the highest. Grassland vegetation was developed in the Songliao Plain of Northeast China, Inner Mongolia Plateau, and the Loess Plateau. The northwest cold air is weakened and the desert is stopped from moving eastward because of the barrier effect of the Helan Mountains. Thus, the grassland vegetation developed well, and the ecosystem structure was more complex than the western desert in these areas. Thus, the anti-interference ability was strong, and the NPP vulnerability level to climate change was high. The NPP vulnerability level of warm temperate deciduous broad-leaved forests in the central-southern Hebei Province was also high, probably because the area is in the transition regions between the warm temperate semi-humid climate and the temperate semi-arid climate, where the interannual fluctuation of temperature and precipitation is large. The potential vegetation in the middle and lower reaches of the Yellow River was mainly the warm temperate deciduous broad-leaved forests, with a more complex eco- 
system structure than the grassland ecosystems and a relatively stable ecosystem function. However, the NPP vulnerability level to climate change was low because of the droughts and floods that frequently occur in these regions. The precipitation variability in the low mountain and hilly areas is large in the southern subtropical evergreen broad-leaved forest regions, which leads to frequent droughts and floods. The Hainan Island and Leizhou Peninsula in the tropics are rich in calories but occasionally cold, where short frost may appear and damage the ecosystem function when the extreme coldness goes south (Zheng, 2008). The NPP vulnerability level to climate change of the potential vegetation in these tropical and southern subtropical areas was higher than that in the middle and lower reaches of the Yangtze River of the central subtropical areas. Precipitation and temperature gradually decreased from the southeast to the northwest. The increasingly harsh natural conditions resulted in the distribution changes of natural vegetation in the Tibetan Plateau. The potential vegetation in the southeastern Tibetan Plateau is alpine meadow, which is alpine grassland in the middle and alpine desert in the northwest. The anti-interference ability of the ecosystems gradually decreased, and the NPP vulnerability to climate change of the potential vegetation gradually increased.

\subsubsection{Possible dominant factor of vulnerability}

The NPP vulnerability to climate change of the potential vegetation is the integration of various climatic factor changes. This paper used the correlation analysis method to determine the most significant climatic factors by comparing the correlation between the single climatic factors and the potential vegetation NPP in each latitude-longitude grid of the past 55 years (Figure 2).
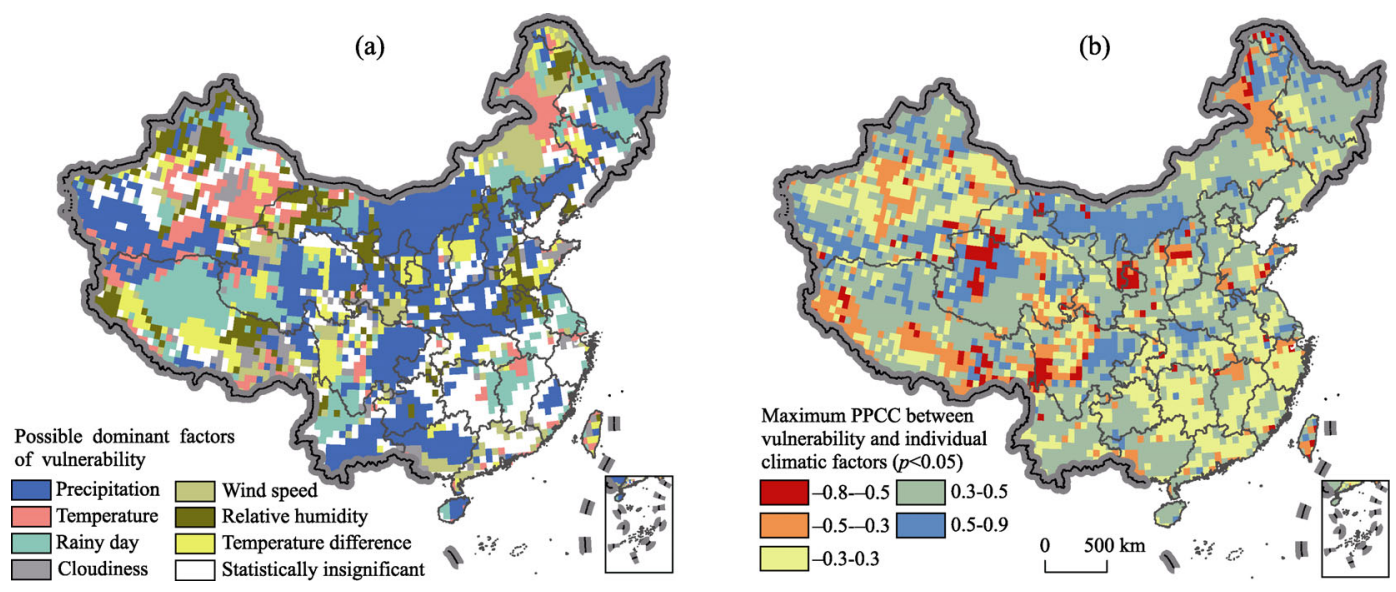

Figure 2 Possible leading factors of vulnerability (a) and the correlation coefficient between these factors and vulnerability (b)

The absolute maximum value of the correlation coefficient between the vulnerability and a single climatic factor was between 0 and 0.3 within $23.6 \%$ of the grids. The weak correlation indicated that the NPP vulnerability of the potential vegetation in these regions was the result of the combined effects of multiple climatic factors, such as the most warm temperate desert areas with the highest vulnerability level. The absolute maximum value of the corre- 
lation coefficient between the vulnerability and a single climatic factor was between 0.3 and 0.5 within $57.7 \%$ of the grids. The result showed a certain correlation between the potential vegetation's NPP vulnerability and the changes of one climatic factor, but the correlation was not high. Furthermore, the influence of other climatic factors on the potential vegetation's NPP could not be ignored. The high NPP vulnerability of the temperate grassland areas and central-southern Hebei Province may have resulted from precipitation changes. A decrease in precipitation would lead to the NPP decrease in the grassland and deciduous broad-leaved forests. The absolute maximum value of the correlation coefficient between the vulnerability and a single climatic factor was between 0.5 and 0.8 within the remaining $18.7 \%$ of the grids. A strong correlation existed between the potential vegetation's NPP vulnerability and the changes in one climatic factor, and this factor may be the dominant climate factor of the regional natural ecosystems. The dominant climatic factor of the potential vegetation's NPP vulnerability of the western Qaidam Basin may be the wind speed, and the dominant climatic factor in the east may be the precipitation. The increased wind speed or decreased rainfall would lead to a reduced desert vegetation NPP. Overall, most of the possible dominant factors for the potential vegetation's NPP vulnerability in China were associated with precipitation, such as the amount of precipitation, rainy days, and relative humidity. The effects of precipitation and relative humidity on the potential vegetation's NPP in China were mostly positive. Rainy days had positive effects on shrub NPP but had weak negative effects on tree NPP. This finding may be related to the increase in rainy days, which improves the amount of precipitation, while reducing the amount of solar radiation (Table 1).

\subsubsection{NPP vulnerability of potential vegetation under future climate change}

Under the scenario of climate change during 2016-2050, the reduced area of the NPP vulnerability level of potential vegetation would account for $22.9 \%$ of the total area of China. The increased area of the NPP vulnerability level of potential vegetation would account for $27.5 \%$, and the remaining $49.6 \%$ would be unchanged (Figure $3 \mathrm{~b}$ ). The area of the regions where the NPP vulnerability level would be the highest increased more, which would account for $21.9 \%$ of the total area of China, including the desert regions of the Tarim Basin in the south of the Tianshan Mountains, and the the Junggar Basin in the northern part of the Tianshan Mountains and the Kunlun Mountains. The areas with higher NPP vulnerability level would be mainly located in the grassland areas of the Loess Plateau and Central Inner Mongolia Plateau, as well as the subtropical evergreen broad-leaved forests areas, with a total area accounting for $12.2 \%$ of China. The areas with lower NPP vulnerability level would be mainly around or inlaid in the areas where the NPP vulnerability level would be higher or highest, with a total area accounting for $23.9 \%$. The areas with the lowest NPP vulnerability level would be mainly located in the cold temperate coniferous forest regions, temperate coniferous and deciduous broad-leaved mixed forest regions, warm temperate deciduous broad-leaved forest regions, Tianshan Mountains, alpine steppe and meadow regions in the Tibetan Plateau, central subtropical evergreen broad-leaved forest regions, and the northern subtropical evergreen and deciduous broad-leaved mixed forest regions, with a total area accounting for $42.0 \%$ (Figure $3 \mathrm{a}$ ). 

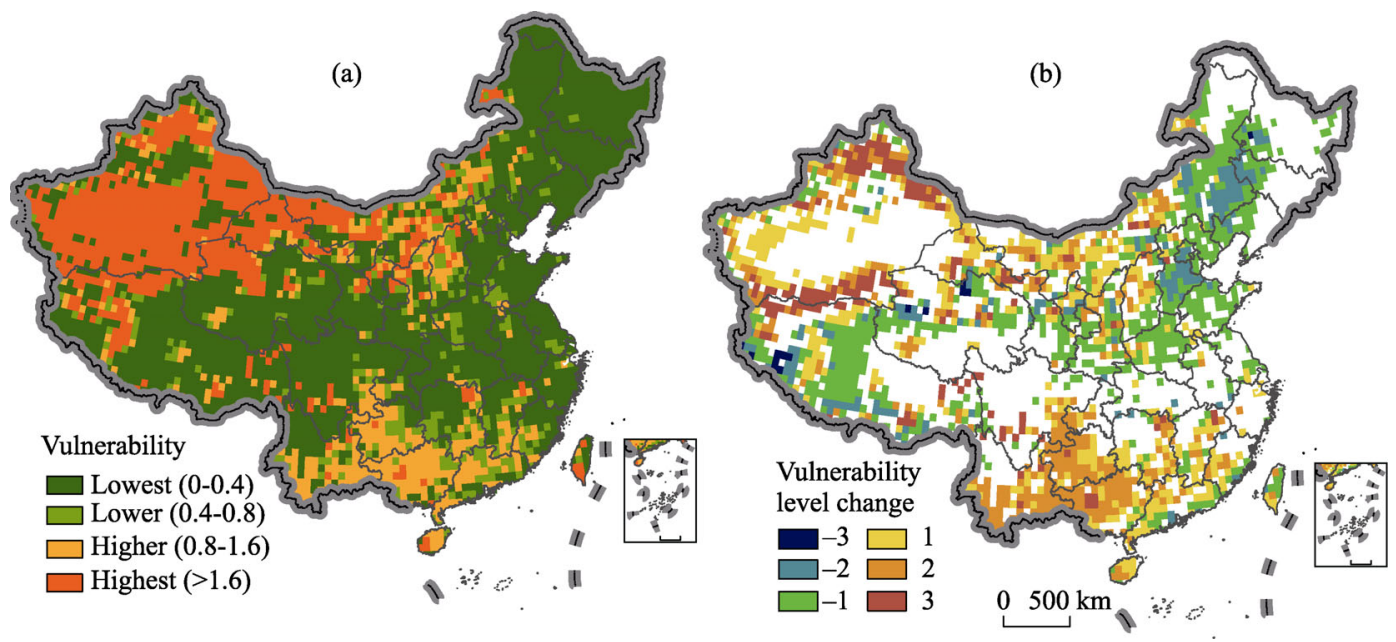

Figure 3 NPP vulnerability under future climate change (a) and rise or fall of the grade compared with the past (b)

In the next 35 years, the NPP vulnerability would significantly increase in the desert areas of Junggar Basin and Kunlun Mountains. This forecast may be explained by the vulnerability of the desert ecosystems with sparse vegetation and simple structure to the adverse effects of climate change and the NPP's tendency for significant fluctuations. The NPP vulnerability of evergreen broad-leaved forests to climate change would increase in southern Yunnan, Guizhou, and western Guangxi, which may be related to the regional precipitation reduction under the future climate change. The NPP vulnerability of the forest-steppe zone to climate change would decrease in the Songnen Plain and Liaohe Plain, where the potential vegetation's NPP vulnerability of some areas would significantly decrease. This forecast may be related to the change in precipitation, rainy days, and temperature. The increase in precipitation and temperature or the decrease of rainy days would result in the regional potential vegetation productivity in these places. The NPP vulnerability of warm temperate deciduous broad-leaved forests to climate change would also decrease, which may be related to the rise in precipitation under the future climate change. The NPP vulnerability of the alpine steppe to climate change in the western Tibetan Plateau would decrease, which may be related to the decrease of precipitation in the future (Table 1).

\section{Conclusions}

Global climate change, as represented by global warming, has been remarkably affecting the ecosystem processes. The results have threatened the human living environment and the sustainable development of social economy. NPP can reflect the quality of the natural ecosystems directly. Using the IBIS model, this study quantitatively evaluated the NPP vulnerability of China's potential vegetation to climate change in the past 55 years (1961-2015) and in the next 35 years (2016-2050). The main conclusions are as follows:

(1) According to the vulnerability assessment, the warm temperate desert ecosystems in the south of the Tianshan Mountains, temperate grassland ecosystems, and alpine grassland ecosystems in the west of the Tibetan Plateau were more vulnerable to the adverse effects of 
climate change in the past 55 years, with a higher potential vegetation NPP vulnerability. Despite the low susceptibility of the forest ecosystems to climate change, the potential vegetation's NPP vulnerability was low. In particular, the NPP vulnerability of the evergreen broad-leaved and coniferous forests was the lowest. Furthermore, the low NPP vulnerability of the potential vegetation in the temperate desert ecosystems in the north of the Tianshan Mountains and alpine grassland ecosystems in the central and eastern Tibetan Plateau to climate change was also observed.

(2) The regional NPP vulnerability of the potential vegetation in $23.6 \%$ of the areas to climate change was the result of the combined effects of several climatic factors in China. That in $57.7 \%$ of the areas had a certain correlation with the changes of one climatic factor. However, the correlation was not high, and the influence of other climatic factors on the vulnerability could not be ignored. That of the remaining $18.7 \%$ of the areas had a strong correlation with the changes in one climatic factor. Most of the possible dominant factors of potential vegetation NPP vulnerability were correlated with precipitation, such as rainy days, precipitation, and relative humidity.

(3) Under the climate change scenarios in 2016-2050, the area of the regions where potential vegetation NPP vulnerability level would decrease would account for $22.9 \%$ of China, mainly including the forest-steppe areas of Songliao Plain, warm temperate deciduous broad-leaved forests areas, and the alpine grassland areas in the central and western Tibetan Plateau. The area of the regions where NPP vulnerability level would increase would account for $27.5 \%$. Among them, the NPP vulnerability would increase significantly in the Junggar Basin temperate desert regions and the alpine desert regions in Kunlun Mountains. The NPP vulnerability level of the evergreen broad-leaved forests in the southern Yunnan, Guizhou, and western Guangxi would also increase.

\section{Discussion}

\subsection{Comparisons with related research results}

The results of this paper were consistent with the results of Ye (1992) and Zhao (1999). The NPP vulnerability level of potential vegetation of the sensitive zone in the Distribution of China's Ecological Sensitive Zone to climate change was generally high. The areas with the highest and high levels of NPP vulnerability were located in the "northern semi-arid and semi-humid fragile zones," "northwestern semi-arid fragile zone," "fragile zone of North China Plain," "southwestern limestone mountainous fragile zone," and "southwestern mountainous fragile zone" of the Distribution of China's Fragile Ecological Environment.

Wu et al. (2007) used the AVIM2 model to simulate the effect of future climate change on the natural ecosystems under the B2 scenario, and the vulnerability of China's natural ecosystems to climate change in the 21st century was predicted. Yu et al. (2008) evaluated the vulnerability of the natural ecosystems in China under the A2 climate scenario using the improved CEVSA model. Zhao and Wu (2014) evaluated the vulnerability of natural ecosystems to future climate change in China. The above studies all discussed the vulnerability of China's natural ecosystems in the future by using the LPJ model to simulate the changes in China's natural ecosystems under future climate scenarios of A2, B2, and A1B. From the results of these studies, the northwestern desert regions and the central-western regions of 
the Tibetan Plateau were predicted more vulnerable to future climate change. This finding is similar to the evaluation results of this study. The vulnerability assessment results were not entirely in agreement in the temperate grassland, warm temperate deciduous broad-leaved forest, subtropical evergreen broad-leaved forest, and tropical rain forest and monsoon forest zones because of the differences in the evaluation index and models. However, the general trend was still the same: the vulnerability in the northwest arid regions and the Tibetan Plateau was significantly higher than that in the eastern monsoon regions.

\subsection{Uncertainty analysis}

The uncertainty in this study came from two aspects, one was related to the data and the other was related to the model. In terms of data, the historical climate data used in this study came from the measured data of meteorological stations, but the existing meteorological data stations in the western regions and in Taiwan were less distributed. Thus, the accuracy of climatic data interpolation in these regions was low. The NPP vulnerability level of potential vegetation to climate change was high in southern Tibetan alpine valley and southern Taiwan. This was probably because of the sparse and late distribution of meteorological stations in these regions. Climatic data scenarios were gathered from the climate model prediction, with its prediction error probably introducing uncertainty to the NPP vulnerability assessment as well. In terms of the model, the simulation accuracy used in this research was $0.5^{\circ} \times 0.5^{\circ} \mathrm{DEG}$ grid, and the average area of each grid was about $2500 \mathrm{~km}^{2}$. In the simulation, the climate data, terrain data, soil data, and simulated ecosystem types in each grid were assumed consistent. Therefore, this paper had a reference value for a study in a national or larger regional scale that could not be used as a reference for a small-scale study.

\section{References}

Cai Yunlong, 1996. Sensitivity and adaptation of Chinese agriculture under global climate change. Acta Geographica Sinica, 51(3): 202-212. (in Chinese)

Fang Chuanglin, Wang Yan, 2016. A comprehensive assessment of urban vulnerability and its spatial differentiation in China. Journal of Geographical Sciences, 26(2): 153-170.

Foley J A, Prentice I C, Ramankutty N et al., 1996. An integrated biosphere model of land surface processes, terrestrial carbon balance, and vegetation dynamics. Global Biogeochemical Cycles, 10(4): 603-628.

Hutchinson M F, 1991. The application of thin plate splines to continent wide data assimilation. Data Assimilation Systems, BMRC Research Report No.27. Melbourne: Bureau of Meteorology.

International Geosphere-Biosphere Program - Data and Information System (IGBP-DIS), 1999. Global Soil Data Task: Spatial Data Base of Soil Properties, Toulouse, France.

IPCC, 2014.Climate Change 2014: Impacts, Adaptation and Vulnerability. Contribution of Working Group II to the Fifth Assessment Report of the Intergovernmental Panel on Climate Change. Cambridge, United Kingdom and New York, NY, USA: Cambridge University Press.

Kucharik C J, Foley J A, Delire C et al., 2000. Testing the performance of a Dynamic Global Ecosystem Model: Water balance, carbon balance, and vegetation structure. Global Biogeochemical Cycles, 14(3): 795-825.

Li Kerang, Huang Mei, Tao Bo et al., 2009. Process Modeling of China's Terrestrial Ecosystem and Its Response to Global Change. Beijing: China Meteorological Press. (in Chinese)

Lieth H, Whittaker R H, 1975. Primary Productivity of the Biosphere. New York: Springer-Verlag.

Liu Yanhua, Li Xiubin, 2007. Fragile Ecological Environment and Sustainable Development. Beijing: The Commercial Press. (in Chinese) 
Metzger M J, Schroter D, Leemans R et al., 2008. A spatially explicit and quantitative vulnerability assessment of ecosystem service change in Europe. Regional Environmental Change, 8(3): 91-107.

Minnen J G, van Onigkeit J, Alcamo J, 2002. Critical climate change as an approach to assess climate change impacts in Europe: Development and application. Environmental Science \& Policy, 5(4): 335-347.

Moss R H, Edmonds J A, Hibbard K A et al., 2010. The next generation of scenarios for climate change research and assessment. Nature, 463(7282): 747-756.

Neilson R P, 1995. A model for predicting continental-scale vegetation distribution and water balance. Ecological Applications, 5(2): 362-385.

Parton W J, Scurlock J M O, Ojima D S et al., 1993. Observation and modeling of biomass and soil organic matter dynamics for the grassland biome worldwide. Global Biogeochemical Cycles, 7(4): 785-809.

Prentice I C, Cramer W, Harrison S P et al., 1992. A global biome model based on plant physiology and dominance, soil properties and climate. Journal of Biogeography, 19(19): 117-134.

Shi Xiaoli. Risk assessment of Chinese ecosystem under climate change scenarios [D]. Beijing: Institute of Geographic Sciences and Natural Resource Research, Chinese Academy of Sciences, 2009. (in Chinese)

Sitch S, Smith B, Prentice I C et al., 2003. Evaluation of ecosystem dynamics, plant geography, and terrestrial carbon cycling in the LPJ dynamic global vegetation model. Global Change Biology, 9(2): 161-185.

Tian Yaping, Chang Hao, 2012. Bibliometric analysis of research progress on ecological vulnerability in China. Acta Geographica Sinica, 67(11): 1515-1525. (in Chinese)

Tüexen R, 1956. Die heutige potentielle natürliche Vegetation als Gegenstand der Vegetationskartierung: mit 10 Tabellen. Angewandte Pflanzensoziologie, 13: 5-42.

Woodward F I, Smith T M, Emanuel W R, 1995. A global land primary productivity and phytogeography model. Global Biogeochemical Cycles, 9(4): 471-490.

Wu Shaohong, Yin Yunhe, Zhao Huixia et al., 2005. Recognition of ecosystem response to climate change impact. Advances in Climate Change Research, 1(3): 115-118. (in Chinese)

Wu Shaohong, Dai Erfu, Huang Mei et al., 2007. Study on the vulnerability of ecological system in China under the future climate change scenario (B2) in 21st century. Chinese Science Bulletin, 52(7): 811-817. (in Chinese)

Wu Shaohong, Huang Jikun, Liu Yanhua et al., 2014. Pros and cons of climate change in China. China Population, Resources \& Environment, 24(1): 7-13. (in Chinese)

Ye Duzheng, 1992. Prestudy of China's Global Change. Beijing: China Meteorological Press. (in Chinese)

Yu Li, Cao Mingkui, Tao Bo et al., 2008. Quantitative assessment of the vulnerability of terrestrial ecosystems of China to climate change based on potential vegetation. Journal of Plant Ecology, 32(3): 521-530. (in Chinese)

Yuan Quanzhi, Wu Shaohong, Zhao Dongsheng et al., 2014. Modeling net primary productivity of the terrestrial ecosystem in China from 1961 to 2005. Journal of Geographical Sciences, 24(1): 3-17.

Yuan Quanzhi, Zhao Dongsheng, Wu Shaohong et al., 2011. Validation of the integrated biosphere simulator in simulating the potential natural vegetation map of China. Ecological Research, 26(5): 917-929.

Zhao Dongsheng, Wu Shaohong, 2014. Vulnerability of natural ecosystem in China under regional climate scenarios: An analysis based on eco-geographical regions. Journal of Geographical Sciences, 24(2): $237-248$.

Zhao Yuelong, 1999. Types Distribution and Comprehensive Improvement of Fragile Ecological Environment in China. Beijing: China Environmental Science Press. (in Chinese)

Zheng Du, 2008. Chinese Eco-geographical Regionalization Research. Beijing: The Commercial Press. (in Chinese) 